\title{
O ROSTO DO OUTRO COMO FACTICIDADE HUMANA: DA LEBENSWELT HUSSERLIANA À ALTERIDADE LEVINASIANA
}

\author{
THE FACE OF THE OTHER AS HUMAN FACTICITY: \\ FROM LEBENSWELT HUSSERLIAN TO LEVINASIAN ALTERITY
}

Grasiela Cristine Celich ${ }^{1}$

\section{RESUMO}

Este artigo tem por objetivo demonstrar a possibilidade de conexão entre fenomenologia, facticidade humana e ética. A possibilidade de conexão entre os conceitos torna-se pertinente a partir da filosofia de Husserl e da filosofia de Levinas, pois ambos se inserem na temática fenomenológica. Desde a descoberta de Husserl, de que a ciência, ao se fundamentar nos conceitos, na razão, desvinculou-se do mundo concreto e das vivências dos sujeitos, perdeu sua dimensão ética. Portanto, Husserl, ao formular o método fenomenológico procurou recuperar a esfera pré-científica da vida. Esfera esta que é caracterizada por ser mais rica e mais ampla que o mundo objetivo da ciência. Diante disso, Levinas, tendo Husserl como mestre, conseguiu, a partir de alguns conceitos husserlianos, como por exemplo, a Lebenswelt, o "retorno às coisas mesmas", encontrar na figura do Rosto do Outro, uma facticidade humana irredutível a toda a apreensão e compreensão pelo conceito. Assim, Levinas expõe que a ética centra-se no Rosto da alteridade. Portanto, para demonstrar essas ideias, apresentam-se, primeiramente, alguns conceitos husserlianos ao que se referem à Lebenswelt, para que, depois possam ser trazidos os conceitos levinasianos que conduzem ao encontro da facticidade humana irredutível no Rosto do Outro.

Palavras-chave: Fenomenologia; Ética; Facticidade Humana.

\section{ABSTRACT}

This article aims to demonstrate the possibility of a connection between phenomenology, human facticity and ethics. The possibility of connection between the concepts becomes pertinente from the philosophy of Husserl and the philosophy of Levinas, since both are inserted in the phenomenological theme. Since Husserl's discovery that science, when based on concepts, on reason, has separated itself from the concrete world and the experiences of the subjects, it has lost its ethical dimension. Therefore, Husserl, in formulating the phenomenological method, sought to recover the pre-scientific sphere of life. This sphere is characterized by being richer and wider than the objective world of science. In view of this, Levinas, having Husserl as his master, managed, based on some Husserlian concepts, such as Lebenswelt, the "return to the same things", to find in the figure of the Face of the Other, na irreducible human facticity to all apprehension and understanding of the concept. Thus, Levinas explains that ethics focuses on the Face of otherness. Therefore, to demonstrate these ideas, first, some Husserlian concepts are presented with regard to Lebenswelt, so that later, the Levinasian concepts that lead to the meeting of irreducible human facticity in the Face of the Other can be brought.

Keywords: Phenomenology; Ethic; Human Facticity.

1 Doutoranda em Filosofia no Programa de Pós-Graduação em Filosofia da Universidade Federal de Santa Maria - UFSM. E-mail: grasielacelich@hotmail.com 


\section{CONSIDERAÇÕES INICIAIS}

Este artigo tem por objetivo apresentar a possibilidade da conexão entre fenomenologia, facticidade humana e ética. A possibilidade de conexão entre os conceitos torna-se pertinente a partir da filosofia de Husserl e da filosofia de Levinas, pois ambos se inserem na temática fenomenológica. Levinas, tendo como mestre, Husserl, conseguiu, a partir de alguns conceitos husserlianos, como por exemplo, a Lebenswelt, o "retorno às coisas mesmas", encontrar no Rosto do Outro, uma facticidade humana irredutível a toda apreensão e compreensão pelo conceito.

Para demonstrar essa ideia, inicialmente, serão apresentados alguns conceitos da teoria Husserliana ao que tange a Lebenswelt, ao mundo da vida, para que, após sejam apresentados os conceitos descritos por Levinas, que estejam em conformidade com a filosofia de Husserl, de modo que se alcance a concepção de que Levinas encontrou no Rosto da alteridade uma facticidade irredutível. Após, será mostrado como que a fenomenologia se relaciona com a ética, a partir da teoria levinasiana da alteridade irredutível a todo e qualquer conceito.

\section{FENOMENOLOGIA HUSSERLIANA: ABERTURA À LEBENSWELT}

Husserl, desde as "Investigações Lógicas", passando pelas “Ideias", pelas "Meditações Cartesianas", até a "Crise da humanidade europeia e a filosofia", ao mesmo momento em que busca o fundamento da ciência, do conhecimento, percebe, também que aquela havia se desviado da razão. A constatação de Husserl foi a de que a ciência, mesmo sendo de grande relevância, acabou se reduzindo a mero conhecimento dos fatos e, diante disso, reduziu o humano a simples coisas. Para Husserl, a atividade científica, atividade da reflexão, da razão, desvinculou-se do mundo concreto dos indivíduos e de suas vivências. Sendo assim, Husserl percebeu que essa situação foi o estopim para uma crise. Para Husserl (1996, p. 50), a ciência não possuía respostas para as necessidades vitais das pessoas e, então, perdeu o objeto de suporte de suas pesquisas; isto é, as experiências pessoais, as intencionalidades que motivaram o agir humano não eram abordadas pelo saber científico. Nesse sentido, havia, para Husserl (1996, p. 85), o fracasso do racionalismo, bem como de toda cultura racional. A razão que havia tomado para si a condução do mundo, da filosofia, da cientificidade, falhou quando esqueceu a subjetividade, o mundo humano, o sujeito atuante no mundo. Além disso, para Husserl (1996, p. 46), a ciência, enquanto dotada de forte objetivismo, perdeu sua dimensão ética, pois não tomou posição sobre o mundo do dever-ser. Portanto, a ciência falhou quando esqueceu-se da Lebenswelt, bem como da subjetividade transcendental.

Nesse sentido, o mundo da vida (Lebenswelt), segundo Husserl, precisa ser recuperado. Trata-se, segundo Husserl, de afirmar que há uma esfera subjetiva pré-científica de vida. Esta esfera pré-científica é caracterizada por ser mais ampla e mais rica que o mundo objetivo da ciência. Aduz-se, conforme escreve Husserl, que, anteriormente ao mundo científico, há um mundo dotado da complexidade do espírito da humanidade; isto é, mundo baseado na multiplicidade e diversidade de vida, de ações, de interesses que constituem o humano. Trata-se de um mundo responsável por formar a unidade da estrutura espiritual do humano, isto é, um mundo de valores fundamentados no sentido da existência pessoal, individual, diversificada e, ao mesmo momento, coletiva das vivências do humano. Diante disso, há, para 
Husserl (1996, p. 42-43), um mundo anterior ao conhecimento científico e, ao mesmo momento, oposto a ele, mas que o fundamenta. Em outras palavras, é a Lebenswelt que precisa fundamentar as ciências. Segundo Husserl (1996, p. 42),

A própria ciência emerge de algo anterior à ela mesma, do campo das experiências pré-científicas e pré-categoriais, ou seja, de um a priori concreto, que chama de Lebenswelt ou Lebensumwelt. [...] O mundo da vida é a fonte do sentido dos conceitos científicos. Se esses não puderem referir-se ao mesmo carecem de sentido.

Trata-se de um mundo que é experimentado, vivenciado pelas pessoas. Mundo no qual as pessoas experimentam uma realidade diversificada e complexa. Ocorre que essa experiência que é abarcada pelo conceito husserliano de Lebenswelt não pode ser reduzida à mera experiência sensível que se tem do mundo físico. Trata-se de afirmar que a experiência a qual o mundo da vida requer é uma experiência que se vincula ao ato da consciência, ou seja, experiência da subjetividade concreta. Portanto, a experiência na qual a Lebenswelt se fundamenta "não é uma soma de objetos (redução das experiências ao mundo das ciências físico-objetivas) [mas] o mundo subjetivo do qual emerge toda a atividade humana" (HUSSERL, 1996, p. 45). Mundo tal que tem sentido e finalidade próprios, do qual emergem os conceitos. Trata-se de afirmar que o mundo da vida tem como centro a dimensão subjetiva do sujeito. Nesse sentido, Husserl, em suas obras filosóficas, defende "o retorno à subjetividade transcendental, afinal, é ela quem pode recuperar o sentido do humanismo e superar o desvio objetivista" (HUSSERL, 1996, p. 46).

Frente a essa constatação, Husserl procurou formular uma fenomenologia de uma maneira diversa do que se tinha até o momento. Inicialmente, nas "Investigações Lógicas" bem como nas "Ideias para uma fenomenologia pura", a fenomenologia husserliana, conforme explicita Zahavi (2015, p. 209) foi puramente descritiva. Após, nas "Meditações Cartesianas", na "Crise das Ciências Europeias" e na "Fenomenologia Transcendental", a fenomenologia voltou-se para a análise do mundo da vida. Trata-se de afirmar que a fenomenologia Husserliana recebeu alterações até se tornar um método descritivo que tem por base descrever as vivências, o vivido e o mundo da vida, retornando ao mundo pré-científico para então, fundar as ciências, o conhecimento e o saber científico. Ao se considerar a fenomenologia como método, considera-se o mundo da vida como ponto de partida, pois ele não é estático, estando, portanto, sempre a se desenvolver conforme a subjetividade concreta. Assim, "na fenomenologia husserliana, o mundo da vida exerce uma dupla função: a) a função de fundamento em relação às ciências; b) função de fio condutor para o retorno da fenomenologia à subjetividade constitutiva do mundo" (HUSSERL, 1996, p. 43). Sendo assim, a fenomenologia por ser método,

Faz aparecer a humanidade como uma única vida de indivíduos e povos, unida por relações somente espirituais, com uma diversidade de tipos de humanidade e de cultura, mas que, por transições insensíveis, se prendem uns aos outros. (HUSSERL, 1996, p. 64).

Diante do fragmento e do que foi exposto até o momento, cabe enfatizar, portanto, que a fenomenologia está voltada ao humano, às características inerentes às pessoas. Ainda, a fenomenologia se relaciona ao espírito social, bem como às suas configurações. Significa aduzir que a fenomenologia está 
Thaumazein, Ano IX, v. 13, n. 26, Santa Maria, p. 25-35, 2020.

voltada à intencionalidade dos vividos, isto é, a fenomenologia não se volta para as coisas naturais como fazem os cientistas, mas nutre seu olhar para os fenômenos, isto é,

Aos múltiplos modos subjetivos de doação graças aos quais temos consciência dos objetos. [Trata-se, aqui, de um] objeto intencional, objeto tal como este se manifesta subjetivamente a um eu, segundo seus distintos modos de doação ou fenômenos. (HUSSERL, 2006, p. 16).

Portanto, o que Husserl está tentando mostrar é que a fenomenologia é responsável por preservar e acolher a facticidade que tem por característica estar aberta ao humano. Para Husserl (1996, p. 43) a fenomenologia do mundo da vida relaciona-se com a subjetividade humana concreta, enquanto material para fundamentar toda e qualquer objetividade. Diante disso, a fenomenologia é capaz de fornecer sentido e validade existencial para a vida da consciência. Assim, com este novo método, Husserl (1996, p. 17-18), ao encerrar o fenômeno na esfera imanente da consciência, sem negar a sua relação com o mundo interior, conseguiu estudar o fenômeno tal como ele se mostra à consciência, propondo o "retorno às coisas mesmas" e, visando o estudo de como o ser aparece no próprio fenômeno. Portanto, Husserl procurou sustentar uma fenomenologia de caráter transcendental e puro, fazendo com que esta possuísse relação com a ontologia.

Assim, Husserl (1929, p. 4) nas "Conferências de Paris", defendeu a legitimidade do "retorno às próprias coisas ou aos estados de coisas numa experiência e evidência originárias", anunciando que o Logos, que toda teoria não pode ignorar a vida pré-científica, a vida que é plenamente vivenciada fora ou para além do conceito. Toda teoria, todo Logos somente é Logos quando considerar as vivências da alteridade. Assim, Husserl tem a pretensão de renovar a filosofia, pois renovando a filosofia, renova-se a ciência. Significa dizer que a renovação das ciências precisa contribuir com a vida que é vivida de forma plena, isto é, precisa contribuir com o bem-estar e a felicidade humana proporcionando melhoria na qualidade de vida. Nesse sentido quando Husserl propõe o "retorno às coisas mesmas", propõe, também, a abstenção do mundo e das coisas enquanto objetos de experiência transcendente.

Sendo assim, Husserl pretende, portanto, voltar-se, orientar-se para o mundo interior, o qual ele chama de transcendental, em detrimento do mundo exterior (transcendente). Nesse sentido, Husserl propõe-se explorar as riquezas da consciência transcendental, pois, segundo ele, o filósofo não precisa recorrer ao mundo transcendente. Assim, Husserl (1996, p. 24) procura descrever o mundo tal como ele se apresenta na consciência e, ao enfatizar o transcendental em detrimento do transcendente, Husserl promove uma abstenção em relação ao mundo exterior. Essa abstenção, Husserl descreve na Primeira Meditação Cartesiana e a chama de epoché fenomenológica (Redução Fenomenológica Transcendental). Então, a fenomenologia, ao se utilizar da epoché, descobre a subjetividade transcendental, purificada de todo e qualquer mundo empírico e natural, podendo compreendê-la na sua doação originária; isto é, a fenomenologia é entendida, portanto,

Como análise descritiva das vivências da consciência depuradas de seus elementos empíricos para descobrir e aprender as essências diretamente na intuição. O efeito da epoché é a redução à esfera transcendental: as vivências puras, a consciência pura com seus correlatos puros e seu eu puro. (HUSSERL, 1996, p. 24-25). 
Trata-se de dizer que é possível, para Husserl, descrever os acontecimentos da vida psíquica, das vivências dos sujeitos. Mas, descrever as vivências dos sujeitos depende de que o sujeito seja um Eu concreto, capaz de intencionar o mundo, de sentir, de participar da multiplicidade e da complexidade da vida. Portanto, ao se descrever as vivências do Eu concreto, é possível se chegar ao mundo dos fatos. E, alcançar o mundo dos fatos, é alcançar um mundo de facticidades humanas concretas, isto é, de individualidades singulares, ou seja, sensações, sentimentos, percepções, reflexões, juízos, atos, ações, vivências humanas participantes do mundo concreto, do mundo que se apresenta para o Eu no qual o Eu está inserido.

Portanto, fornecer atenção para as facticidades humanas, é fornecer relevância para as vivências que são experienciadas pelo Eu. Ou seja, o "ego não percebe a si mesmo unicamente como a vida que transcorre, mas também como Eu, Eu que vive isso ou aquilo, Eu idêntico que vive tal ou tal cogito" (HUSSERL, 2001[1931], p. 82). Trata-se de afirmar que a fenomenologia preocupa-se com a vida concreta da consciência que se perfaz em fatos, infinidades, complexidades e diversidades sempre novas, jamais compreendidas, inteiramente, pelo Logos.

Assim, a fenomenologia, tal como Husserl a concebeu, implica em defender a vida que é vivenciada fora do Logos, fora da teoria, pois essa vida abrange a multiplicidade de sujeitos, tal como eles se constituem para si e, portanto, para Husserl, há um mundo objetivo, isto é, um mundo de experiências reais e concretas, na qual cada pessoa humana é vista e compreendida como pessoa humana.

Exposto acerca da fenomenologia husserliana e de como ela fornece relevância ao mundo da vida, da Lebenswelt, nos próximos itens será tratado sobre a fenomenologia de Levinas e como que este alcança a concepção de que o Outro é uma facticidade irredutível ao Eu, a partir de Husserl.

\section{FENOMENOLOGIA LEVINASIANA: O PARA ALÉM DA HERANÇA HUSSERLIANA}

Levinas, mesmo herdando de Husserl aspectos da fenomenologia, ele também possui suas peculiaridades em relação ao mestre. Essas peculiaridades podem ser percebidas nas várias obras de Levinas, especialmente em "Théorie de l'intuition dans la phénoménologie de Husserl" e "Descobrindo a Existência com Husserl e Heidegger", principalmente nos seguintes artigos: "Reflexões sobre a técnica fenomenológica", "A Ruína da Representação", "Intencionalidade e Metafísica" e "Intencionalidade e Sensação".

Husserl, embora trouxesse novidades ao modo de filosofar, formulando novo método - a fenomenologia - fazendo com que esta inaugurasse a análise da consciência para que assim os conceitos, o Logos da ciência fosse fundado e esclarecido a partir do mundo pré-teórico, o qual é fonte dos conceitos fundamentais e das teorias, Levinas (1959) compreendeu que Husserl se manteve relacionado à ontologia. Em outras palavras, Husserl mesmo que forneceu, através da análise das intuições um ensinamento sobre o Ser, bem como tenha renovado o conceito de transcendental quando apresentou a fenomenologia e quando realizou uma argumentação de que há sempre algo de transcendente no objeto quando se tenta apreendê-lo, mesmo que Husserl tenha defendido o "retorno às coisas mesmas", sofre a crítica, por parte de Levinas, de que ainda se manteve ligado à ontologia. Porém, embora Levinas formule crítica para alguns aspectos da teoria husserliana, ele aproveita outros aspectos, como por exemplo, a redução 
transcendental, a facticidade, a intencionalidade e o próprio sentido fenomenológico proporcionado pelo novo método filosófico.

Ocorre que, Levinas, ao ser herdeiro de Husserl nos aspectos exemplificados acima, ele estendeu a fenomenologia para além da ontologia, bem como da própria filosofia husserliana, preocupando-se com uma facticidade humana irredutível, centrada no Outro, na alteridade. Por isso, de acordo com Murakami (2002), a antropologia fenomenológica foi o método de Levinas. A antropologia fenomenológica se relaciona com situações e fatos concretos vivenciados e experienciados pela singularidade; isto é, a antropologia fenomenológica tem por base a vida humana, a facticidade humana que é vivida concretamente.

Nesse sentido, na concepção de Murakami (2002, p. 14-15), Levinas não se limitou a formular uma teoria para a alteridade, mas se preocupou com uma teoria da experiência do mundo sensível, isto é, do mundo da vida, das experiências e vivências do Outro, experiências da subjetividade concreta. Diante disso, Murakami (2002, p. 138) entende que Levinas através do conceito de Outro, de alteridade, de proximidade, descobriu que o Outro não é apenas um corpo, um ego, mas é uma singularidade diferente das outras singularidades. Trata-se de aduzir que, para Murakami (2002), Levinas defende que o Outro, que cada sujeito, é uma facticidade originária e irredutível, diferente das outras facticidades e, portanto, sujeito humano, sujeito concreto, sujeito de vivências e experiências concretas, pré-originárias.

Isso significa dizer que, quando Levinas apresenta o conceito de alteridade radical, de Outro, de facticidade humana, mesmo que ele se afirme no mundo pré-teórico, como fez Husserl, Levinas vai além da ontologia. Assim, já se diferencia de Husserl. Conforme escrito anteriormente, o mundo pré-teórico é um mundo essencialmente baseado na experiência humana. Entretanto, a experiência humana de que trata a fenomenologia, não está relacionada ao empirismo clássico e, portanto, a palavra "experiência", para a fenomenologia, não significa que se trata dos frutos de uma experiência qualquer, de uma "experiência-que-aspira-a-uma-verdade" (LEVINAS, 1959, p. 196). A palavra experiência, aqui, toma um significado mais profundo e originário. Trata-se de uma virada conceitual, de uma origem transcendental, que é feita pela fenomenologia, mostrando que o comportamento, os atos humanos são compreendidos como experiência original. Nesse sentido, o mundo sensível, o mundo da vida que é encontrado com a epoché husserliana, bem como o "retorno às coisas mesmas", ganham um sentido de destaque para Levinas. Nesse viés, pelo fato de Levinas se preocupar com o mundo pré-teórico, ele defende uma subjetividade radical e originária no Rosto do Outro, isto é, para Levinas há um "domínio subjetivo mais objetivo do que qualquer objectividade" (LEVINAS, 1959, p. 159).

Essa ideia trazida por Levinas, de que há uma "subjetividade mais objetiva do que qualquer objetividade" relaciona-se à fenomenologia, visto que, quando esta propõe o "retorno às coisas mesmas", às vivências da consciência, faz com que o pensamento filosófico volte para suas origens, para a realidade; isto é, a filosofia ao considerar a fenomenologia, teria como base o fundamento de uma experiência comum que levaria em consideração todos os sujeitos concretos e não mais apenas teorias singulares sem um fundamento comum. Além disso, afirmar que há um "domínio subjetivo mais objetivo do que qualquer objetividade" é instar a concepção de que a fenomenologia permite "uma reconstituição do ser concreto do objeto, um regresso a tudo aquilo que foi esquecido na atitude de fixação no objeto" (LEVINAS, 1959, p. 141) e, por isso Levinas afirma que ao se recorrer à subjetividade mais objetiva do que todo conceito, do que toda teoria, do que toda objetividade, há a marca da atividade transcendental que conduz, na 
teoria levinasiana, conforme compreende Murakami (2002), para uma consciência não-intencional. Nesse sentido, Levinas se difere de Husserl e, portanto, apresenta e defende uma nova via fenomenológica. Via fenomenológica que está calcada na consciência não-intencional.

Portanto, para Levinas, a consciência não-intencional acompanha, sob ponto de vista de desinteressamento a constituição do mundo e do fluxo de experiências e, então, deste fluxo ela não participa diretamente. Nesse sentido, a consciência sendo não-intencional conduz à dimensão transcendental, anterior ao Ser e, por consequência, conduz para a via da instituiç̧ão da subjetividade concreta e, marca a singularidade do sujeito. Nesse sentido, apresenta-se à subjetividade concreta uma vida pré-teórica, vida realmente concreta. Segundo Levinas (1984, p. 75-76),

É uma vida de ação e de sentimento, de vontade e de julgamento estético, de interesse e de desinteresse, etc. De fora, o mundo correlativo dessa vida, objeto de contemplação teórico, mas também mundo de sentido, mundo de ação, de beleza e de bondade.

Assim, mesmo sendo a consciência não-intencional, segundo Murakami (2002, p. 57) uma percepção imediata e interna ao sujeito, ela se dá ao ato intencional. Entretanto, para Levinas, esse dar-se ao ato intencional, não significa afirmar a correlação entre sujeito e objeto conduzindo para uma unidade ideal da multiplicidade no interior da ontologia como em Husserl. Para Levinas, a intencionalidade mesmo que realiza um movimento subjetivo, movimento transcendental, ela não faz guiada pelo Ser, mas pelo Outro, pela alteridade. Nas palavras de Levinas (1959, p. 167),

O Outro guia o movimento transcendental sem se oferecer à visão, a qual, precisamente seria sempre extravasada pelo próprio movimento transcendental que deveria definir. O movimento transcendental recebe doravante uma estrutura totalmente diferente da polarização sujeito-objeto, que caracteriza a intuição. O grande contributo da fenomenologia husserliana deve-se a essa ideia de que a intencionalidade ou a relação com a alteridade não se imobiliza ao polarizar-se como sujeito-objeto.

Ao se perceber, portanto, que, a fenomenologia, ao se levar em consideração as concepções introduzidas por Levinas, acaba por possuir a intencionalidade relacionada à práxis e não mais em uma intencionalidade objetivante. Nesse sentido, ao relacionar a intencionalidade com a práxis, Levinas propõe uma intencionalidade originária, assim se diferenciando um pouco de Husserl. Nesse viés, para Levinas, a intencionalidade original tem por finalidade reabilitar o sensível e fornecer espaço primordial à sensibilidade.

A sensibilidade, portanto, é um princípio, uma primeira impressão (Urimpresion), é o aqui e agora, o início absoluto, a individuação do sujeito, a origem do sensível, do pré-teórico que fundamenta todo conceito. Ela é a origem, é o "ponto zero" da vida pré-teórica. Trata-se de enfatizar que a sensibilidade, enquanto Urimpresion, conforme expõe Levinas (1959, p. 144) "marca o caráter subjetivo do sujeito" e, portanto, aí se relaciona com a intencionalidade originária. Nesse sentido, a Urimpresion, 
Thaumazein, Ano IX, v. 13, n. 26, Santa Maria, p. 25-35, 2020.

Transpassibilidade. A impressão originária como presente absoluto é transpassável ao acontecimento inesperado, isto é, ao transpossível [...] da impressão originária no fluxo temporal é o encontro da dimensão da identidade simbólica e da dimensão proto-simbólica da impressão original. (MURAKAMI, 2002, p. 48-49)

Assim, há, para Levinas, segundo Murakami (2002, p. 35) uma estrutura de interação fundamental, que irá marcar o fluxo de consciência e, por consequência, apelar à subjetividade, descobrindo que na dimensão do sensível há uma riqueza infinda, multiplicidade tal que não se subordina aos atos objetivos, à ontologia, ao conceito. Para Murakami (2002), Levinas encontrou a individualidade do sujeito.

Além disso, é relevante afirmar que, para Levinas, a subjetividade concreta está relacionada à temporalidade. Portanto, Levinas, ao tratar sobre o tempo que se relaciona ao fluxo de consciência, apresenta a concepção de um tempo diacrônico. Assim, a subjetividade é a diacronia e, por consequência, a diacronia é uma estrutura que torna possível o encontro com a contingência mais contingente, isto é, com o Outro, sem que este seja reduzido. O tempo diacrônico, para o filósofo não significa uma temporalidade irredutível, impossivel de sincronização, mas remete à proto-impressão, à genesis spontanea, onde já se antevê a figura do Outro. E, quando se trata da figura do Outro, na concepção de Levinas, está-se, portanto, tratando sobre a ética.

\section{FACTICIDADE, FENOMENOLOGIA E ÉTICA: CONEXÃO CENTRADA NO ROSTO DA ALTERIDADE}

Para refletir sobre a relação entre fenomenologia e ética, bem como com a facticidade humana, é preciso afirmar que, como Levinas (2002, p. 41) se preocupa em encontrar uma facticidade humana que seja irredutível à ontologia, então é preciso tratar acerca do conceito de despertar.

Para Levinas, a redução transcendental husserliana, seria um despertar, uma démarche (LEVINAS, 2002, p. 49), que rompe com a identidade do Ser, ou seja, o despertar rompe com o Mesmo. Esse romper com o Mesmo, é romper com a totalidade, com a tematização, é despertar para a vida, às vivências humanas. O despertar implica em realizar várias e novas "reduções" de modo que não se retorne ao Mesmo totalizante, mas que se reative "intenções entorpecidas, reabra horizontes esquecidos [pelo conceito], desconcertando o Mesmo no seio de sua identidade" (LEVINAS, 2002, p. 49). Assim, esse despertar romperia, também, com a racionalidade que se ancora em sabres, em certezas, em conceitos. Despertar o Eu seria reanima-lo para a vida concreta, para os horizontes humanos concretos que foram perdidos no anonimato do Ser. Despertar seria, portanto, arrancar, desenraizar o Eu de sua terra. Seria questioná-lo em sua identidade de Eu. Despertar, portanto, conforme escreve Levinas (2002, p. 97) é ter, em nós, uma ideia inabarcável. É ser tomado pelo pensamento que permite pensar mais do que ele pode pensar. Trata-se de uma ideia que significa,

Uma significância anterior à presença, a toda presença, anterior a toda origem na consciência e, assim, an-árquica. [...] Ideia que significa por uma significância mais antiga que sua exibição, que não se esgota na exibição, que não tira seu sentido de sua manifestação, rompendo assim com a coincidência do Ser e do aparecer em que para a filosofia ocidental, reside o sentido ou a racionalidade. (LEVINAS, 2002, p. 97) 
A partir desse fragmento, Murakami (2002, p. 299), ao interpretar Levinas, aduz que o Ser é despertado por algo ou por alguém que não ele mesmo. O despertar do Ser, o seu desenraizamento, é externo. O despertar, para Murakami (2002) designa, sobretudo, o momento transcendental que proporciona a produção da multiplicidade e das diferenças humanas. Nesse sentido, o despertar traz a vivacidade da vida para Levinas (2002, p. 52). Portanto, para o filósofo, o despertar implica no não repouso. Com o despertar, a totalidade do Mesmo, a tematização e o Ser são postos em questão e, então, aqui a ontologia é rompida pelo Outro. O Eu, portanto, antes enraizado em sua terra, desembriaga-se de sua identidade e de seu ser, sai do Mesmo, pois foi despertado pelo Outro, pela alteridade. Nesse momento, há o que Levinas (2002, p. 44) denomina de transcendência na imanência, pois no despertar, feito pelo Outro ao Mesmo, existe uma relação sempre aberta, na qual o Outro não se reduz ao Mesmo, nem à sua identificação, nem à sua conciliação. O despertar faz com que o Mesmo não assimile o Outro e nem o aliena. E, o Mesmo também não sofre assimilação, apenas é chamado a manter uma relação de proximidade com o Outro. Essa relação é ser despertado pelo Outro. O despertar para Levinas (2002, p. 214) não é interpretado como intencionalidade. O despertar representa uma alteridade irredutível ao Ser, alteridade que resiste a toda sincronização, que resiste à tematização. Resiste à noção noema-noese. Assim, ser despertado pelo Outro, é ser despertado pelo Rosto, é estar em proximidade com o próximo, em intercâmbio com o Outro, totalmente irredutível ao Eu.

Despertar é, também, conforme expõe Levinas (2002, p. 181), estar diante de uma transcendência originária que se fundamenta no concreto, se funda em uma facticidade humana que se mostra no Rosto do Outro. Assim, o Rosto não é responsável por sintetizar como se unisse cada parte ao todo. O Rosto, conforme escreve Levinas (1961[2011]), na obra Totalidade e Infinito, reporta-se a Outro, aquele que vem do infinito e "me faz face". O Rosto exprime-se. Ele recusa o englobamento, recusa a compreensão, inclusive recusa a comparação. O Rosto é diferença absoluta, é assimetria que vem da altura, é a não-violência e, portanto, ao anunciar a inviolabilidade ética da alteridade, traz consigo a instituição do sujeito concreto, enquanto singularidade humana concreta e, fundamento das vivências humanas concretas, anteriores ao Logos e ao conceito. O Rosto, conforme entende Levinas (1961[2011]) é expressão original e, portanto, resistência ética. Então, toda singularidade, toda facticidade humana já é ética e, ao mesmo momento, Rosto.

Nesse sentido, como o Rosto reporta-se à uma facticidade concreta, humana e que é irredutível ao Ser e, como ele traz a ética, então, para Levinas há a instituição de um sujeito concreto compreendido como singularidade humana. Sujeito que é portador de uma facticidade diversa e irredutível à toda e qualquer outra facticidade. Sujeito que é único. Nesse sentido, o Rosto se manifesta como facticidade do Outro e, se encontra em sua significação ética. Portanto, a abertura fenomenológica, promovida por Levinas, define-se como a instituição do sujeito concreto. Sujeito de unicidade, sujeito de "carne e osso". Diante disso, Murakami (2002) compreende que Levinas foi o filósofo que realmente forneceu relevância à alteridade descobrindo a via de existência de uma facticidade originária e irredutível. Isso significa que a formulação do conceito de facticidade originária remete para a instituição de um sujeito concreto; isto é, sujeito possuidor de uma singularidade humana irredutível, inapreensível diante de todas as demais facticidades. Nas palavras de Murakami (2002, p. 138), 
Thaumazein, Ano IX, v. 13, n. 26, Santa Maria, p. 25-35, 2020.

A grande descoberta de Levinas quanto à questão da relação com o Outro, é que o Outro não é apenas o outro Leib, o outro ego (outro ponto zero como eu), mas ele sempre já é considerado uma facticidade (singularidade em sua unicidade e contingência com a possibilidade de sentido) e que essa facticidade [...] se distingue categoricamente de minha facticidade e da facticidade dos fenômenos do mundo. A facticidade do Outro tem uma estrutura diferente da minha facticidade. [...] Levinas descobriu a facticidade original e irredutível.

Diante disso, se a fenomenologia, desde Husserl, tem por objeto a vida que é vivenciada no pré-teórico com ancoramento na práxis, na emoção e na valorização das vivências humanas originárias, então, para Levinas (1959), enquanto leitor e crítico de Husserl, as vivências humanas tem sua origem no subjetivo (subjetividade). Assim, como Levinas (1965, p. 178) já descobriu que a facticidade humana é irredutível a toda e qualquer outra facticidade, então, para ele, a fenomenologia tem por objetivo reativar o horizonte sensível, o horizonte esquecido no qual esta facticidade se ancora. Há, segundo Levinas, a ideia de que a fenomenologia depende da vida concreta e, nesse viés, a fenomenologia, revela-se como facticidade. Portanto, há uma relação direta entre fenomenologia e facticidade. Facticidade que se revela na vida concreta dos sujeitos e, por consequência há uma subjetividade que é sempre transcendental. Entretanto, enquanto Husserl compreende esta facticidade relacionada à ontologia, Levinas coloca-a além do Ser. Há, para Levinas, uma facticidade que se revela como pura alteridade. Nesse momento, Levinas já se diferencia de Husserl. Por já se diferenciar de Husserl, Levinas já anuncia que a ontologia sempre tematizou a alteridade no conceito e que, portanto, "retornar às coisas mesmas" não é voltar-se ao Ser, mas voltar-se para além dele. Nas palavras de Dartigues (2008, p. 137),

O verdadeiro primordial, as famosas "coisas mesmas" às quais cumpre voltar, é o Outro tal como o manifesta o Semblante (Visage) em sua alteridade irredutível a toda constituição em mim ou num elemento neutro; apenas do Outro, cuja face antecede e comanda todo discurso, poderá vir o único discurso filosófico que seja também, desde o início, uma ética.

Conforme o fragmento, o que se tem com Levinas, de acordo com Dartigues (2008) é que o Rosto é o portador das "coisas mesmas", da alteridade irredutível a todo e qualquer Logos. O Rosto traz as vivências do Outro. O Rosto é fenômeno e promove a ética. Para Levinas (1949, p. 13), conforme Husserl apresenta, "a fenomenologia constitui para as pessoas um modo de existir no qual elas cumprem o seu destino de espírito". Entretanto, cumprir o destino de espírito significa que a fenomenologia lança base para a ética, proporcionando que os sujeitos tomem consciência de si mesmos e, por consequência, assumam a responsabilidade de si próprios. Nesse sentido, a fenomenologia preocupa-se com o vivido, com as sensações. Trata-se de que a fenomenologia, ao lançar sentido à vida espiritual, à vida ética, define-se pelas vivências, pelo "retorno às coisas mesmas" e não pelo pensamento reflexivo, nem pelo simples pensar empírico. Nesse sentido, ao que se pode perceber é que há uma relação entre facticidade humana (compreendida na figura do Rosto, da alteridade) com a fenomenologia e a ética. 


\section{CONSIDERAÇÕES FINAIS}

Neste artigo foi visto que há conexão entre a filosofia de Husserl e de Levinas, especialmente ao que se referem à Lebenswelt, a uma vida tomada para além do conceito. Levinas herda de Husserl a fenomenologia e, para além da ontologia, descreve uma facticidade humana irredutível a qualquer conceito e sistema, centrada na alteridade. Além disso, ao tratar sobre a facticidade humana, Levinas clama por uma ética centrada no Rosto do Outro.

\section{REFERÊNCIAS}

CERBONE, D. Fenomenologia. Petrópolis: Vozes, 2012

DARTIGUES, A. 0 que é a fenomenologia? 10. ed. Editora: Centauro, 2008.

HUSSERL, E. Meditações Cartesianas: Introdução à fenomenologia. São Paulo: Madras, 2001. Conferências de Paris. Disponível em: www.lusosofia.net Crise da Humanidade Europeia e a Filosofia. Porto Alegre: EDIPUCRS, 1996. Ideias para uma fenomenologia pura (Ideias I). São Paulo: Ideias \& Letras: 2006. Investigações Lógicas: sexta investigação. São Paulo: Abril Cultural, 1980.

LEVINAS, E. Descobrindo a existência com Husserl e Heidegger. Lisboa: Instituto Piaget, 1949. Intencionalidade e Metafísica. In: Descobrindo a existência com Husserl e Heidegger. Lisboa: Instituto Piaget, 1959.

A ruína da representação. In: Descobrindo a existência com Husserl e Heidegger. Lisboa: Instituto Piaget, 1959.

. Intencionalidade e Sensação. In: Descobrindo a existência com Husserl e Heidegger. Lisboa: Instituto Piaget, 1965.

. Reflexões sobre a "técnica" fenomenológica. In: Descobrindo a existência com Husserl e Heidegger. Lisboa: Instituto Piaget, 1959.

Théorie de l'intuition dans la phénoménologie de Husserl. Paris: Vrin, 1984.

Totalidade e Infinito: Ensaio sobre a exterioridade. 3. ed. Edições 70, 2011.

. Entre Nós: Ensaios sobre a alteridade. 5. ed. Petrópolis: Vozes, 2010

MURAKAMI, Y. Lévinas phénoménologue. 2002

ZAHAVI, D. A fenomenologia de Husserl. Rio de Janeiro: Via Verita, 2015. 
